\title{
Recent Karyological Research on Cave Planarians from Europe
}

\author{
by
}

Nicole GOURBAULT*

\section{INTRODUCTION}

Hitherto very few studies have dealt with the cytotaxonomy of the hypogeous freshwater Triclads. This paucity results from the difficulties of collecting these species in subterranean biotopes, of keeping them in laboratory-culture and of obtaining cocoon-depositions. Most of these taxa are known only from one locality, and usually few specimens are obtained.

Nevertheless, in an attempt to contribute to our understanding of the relationships and phylogeny of the group, I assumed it to be important to undertake such karyological research in a comprehensive way.

I started this research under the guidance of Professor Mario Benazzi; he introduced me to the efficient techniques and participated in most of my work, for which I am very grateful.

The cave Planarians are classified within the two families Planariidae and Dendrocoelidae; most in Europe belong to the last one. The first data referring to the chromosome numbers of some species of the two families were obtained by Dahm $(1958,1961,1964)$ and can be summarised as follow:

\section{Planariidae}

Phagocata Leidy

- vitta (Dugès): various karyotypes with numbers from 21 to 70 have been recorded; these numbers are multiples of the basic number 7 .

Most of the populations are asexual: $2 \mathrm{n}=28$ has been found for the populations with sexual reproduction.

- albissima (Vejdovský): $\mathrm{n}=18,2 \mathrm{n}=36$.

- paravitta (Reisinger): $n=17,2 \mathrm{n}=34$.

- dalmatica (Stanković and Komárek): $\mathrm{n}=16,2 \mathrm{n}=32$.

* Laboratoire Souterrain du CNRS, 09410 Moulis and Muséum National d'Histoire Naturelle, Paris, France. 
Atrioplanaria de Beauchamp.

- racovitzai (de Beauchamp): chromosome number $=52$.

- species from Sardinia, $c f$ Benazzi (1938): chromosome number $=46$.

\section{Dendrocoelidae}

Dendrocoelum Oersted

- album (Steinmann): $\mathrm{n}=14,2 \mathrm{n}=28$ (troglophile species).

- tubuliferum de Beauchamp: $\mathrm{n}=16,2 \mathrm{n}=32$.

- infernale (Steinmann): $2 \mathrm{n}=32$ (16 bivalents in male meiosis, according to Aeppli, 1951).

\section{TECHNIQUES}

The chromosome sets were studied on mitoses of neoblasts of regenerative blastemas first submitted to action of colchicine, then stained in lacto-acetic-orcein and squashed. The germ lines are observed in squashed gonads stained in the same way.

The relative lengths (length of each chromosome $\times 100 /$ total length of the haploid genome) and centromeric indices (length of the shorter arm $\times 100 /$ total length of the chromosome) were obtained by chromosome measurements from enlarged camera lucida drawings. The elements were classified according to the nomenclature established by Levan et al. (1964).

\section{REVIEW OF THE RESULTS}

\section{Planariidae}

Among the Planariidae, the investigations began (Benazzi and Gourbault, 1973) with the studies of Plagnolia vandeli de Beauchamp and Gourbault.

This is the most significant hypogeous species of the family as confirmed by its morphology and very low metabolism (Gourbault, 1972). The chromosome set consists of 44 metacentric or submetacentric elements whose lengths decrease gradually and regularly (Fig. 1, A). Benazzi and Gourbault have suggested that this karyotype might be interpreted as corresponding to a tetraploid condition; however, karyological evidence is lacking. All auxocytes contain 22 bivalents, the pachytene stages being the most frequently found, diplotene and metaphase being rare.

Some groundwater dwelling populations of Phagocata vitta from the South of France (Benazzi and Gourbault, 1975) have been shown to possess $n=17$ and $2 n=34$ (Fig. 1, B). The gametogenesis in both male and female lines is quite normal and the first chromosome pair is always characterized by very large metacentric elements. This complement corresponds obviously to a diploid condition. Therefore these Mediterranean populations cannot be included within the polyploid series described by Dahm (1958) for the Northern European populations of the same species.

An analysis of two species of the genus Atrioplanaria, A. delamarei Gourbault and Atrioplanaria sp. from Italy, is now in progress. The number of their very intricate and crowded chromosomes is difficult to ascertain but is about 80 to 110 in these taxa. 


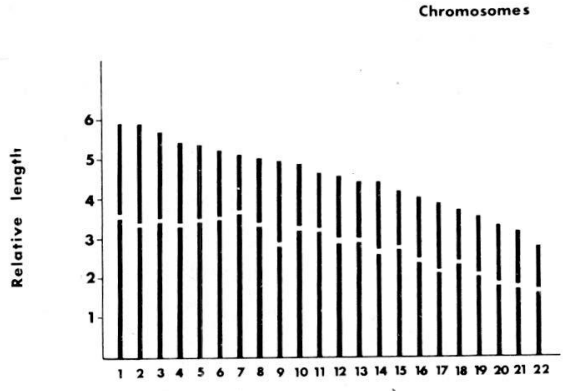

A

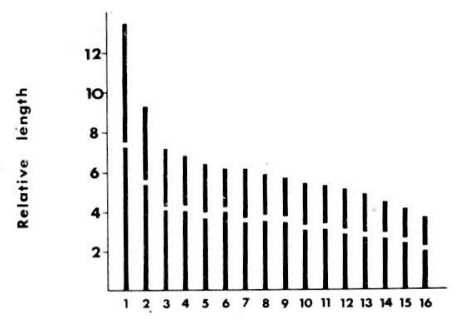

C

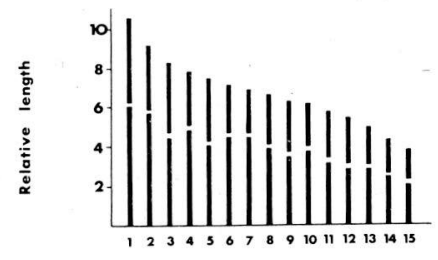

E

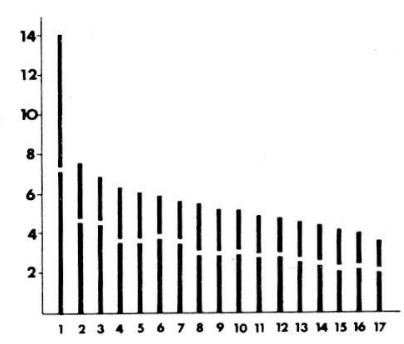

B

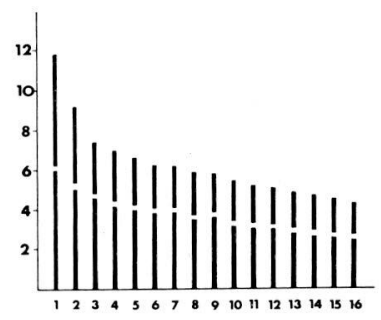

D

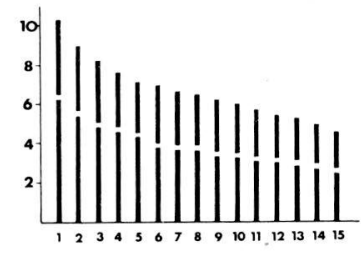

$\mathrm{F}$

Fig. 1. Idiograms of some cave Planarians: A. Plagnolia vandeli; B. Phagocata vitta; C. Dendrocoelum tuzetae; D. D. coiffaiti; E. Dendrocoelopsis beauchampi; F. D. chattoni.

\section{Dendrocoelidae}

The Dendrocoelidae, which are well known for their ability of adaptation to underground habitats and life, mostly belong to the two genera Dendrocoelum and Dendrocoelopsis Kenk.

Dendrocoelum tuzetae Gourbault and Dendrocoelum coiffaiti de Beauchamp are closely related; furthermore their karyotypes can readily be compared (Gourbault, 1975). Both chromosome sets consist of 32 metacentric or submetacentric elements. They are easy to pair and are characterized by the presence of a large pair of typical metacentric chromosomes (Fig. 1, C and D). The second one is slightly shorter; the length of the 14 other pairs decreases 
gradually. The gametocytes possess 16 bivalents whose size variations are in agreement with those observed for the chromosomes.

Dendrocoelopsis beauchampi (Gourbault) possesses 30 chromosomes; the recognition of the homologues is often difficult (Benazzi and Gourbault, 1974). Because of their morphology they are included in the range between the metacentric and submetacentric elements (Fig. 1, E). The meiosis is regular and 15 bivalents are found in all the auxocytes examined.

The data obtained for Dendrocoelopsis chattoni (de Beauchamp) are complex. The chromosome number does not seem to be constant. In somatic mitoses it may be 28,30 or infrequently 32 . Most of the elements are metacentric (Fig. 1, F). The gametogenesis is normal in both lines. The spermatocytes contain 15 or 16 bivalents but the oocytes seem to possess a permanent number of 15 bivalents. These discrepancies can be explained by the phenomena of aneuploidy; so it is possible to conclude that the diploid number of the species is 30 (Gourbault and Benazzi, 1974).

The karyotypes of all these analysed species are included in figure 1 to facilitate direct comparison of the morphology of each of the elements.

\section{CONCLUSIONS}

It is certainly too early at this time to make definite conclusions. Six species only have been thoroughly studied by us, and not many more by Dahm; these data are insufficient to allow general cytotaxonomical inferences. However, some important points can be clarified chiefly with regard to the high number of chromosomes.

The haploid complement of sexual cave-dwelling planarians is found to be 14, 16, 17 or 18 for Phagocata, 16 for Dendrocoelum and 15 for Dendrocoelopsis; for Plagnolia it is 22, but it might be 11 if a tetraploid condition is assumed. On the contrary, in the epigeous taxa, the haploid number is 4 or 8 for Dugesia 6, 7, 8 or 9 for Polycelis and 9 for Planaria. But for Planaria, high chromosome numbers possibly occur in these epigeous species. For instance in Crenobia high chromosome numbers are to be found ( 28 to 63 ) but they seem to be a multiple of the basic number 7. In sexual forms of Dugesia and Polycelis high numbers are caused by gynogenesis-linked polyploidy ( $c f$. for a summary Benazzi and Benazzi-Lentati, 1975).

Polyploidy occurs, according to Dahm, in some mostly troglophile and asexual populations of Phagocata vitta from Northern Europe. This condition could also explain the complements found in the strictly hypogeous genus Atrioplanaria in which numerous tiny chromosomes are indicative of complex sets.

However, none of the other data referring to hypogeous forms can be interpreted on the same grounds, chiefly because of the presence of a highly-differentiated pair of large chromosomes in most of the karyotypes; in such cases the diploidy is well supported by normal gametogenesis processes.

Even if a karyological mechanism of evolution fails to explain the 
occurrence of high chromosome numbers, the phenomenon could be assumed to be related to the subterranean habitat. As far as I know, very few studies have been involved with the karyology of hypogeous taxa in different animal groups. Henry (1972) has shown that all the cave Asellids display 24 chromosomes which is the highest number found for this group, and concluded that the chromosome sets of the recent epigeous species with few chromosomes would be originated from these of primitive cave species through a process of evolution that has not been so far elucidated. A similar uniformity of the diploid complement $(2 n=50)$ has been found for every species of the genus Niphargus thus differentiating it from the epigeous Gammarids (Reygrobellet, 1974). For some Opiliones, two of which are cave-dwellers, Juberthie (1956) noticed an increase in chromosome sizes and a reduction in chromosome numbers in the most evolved families. The data obtained for cave Orthoptera relate to troglophile species only (Saltet, 1967).

Even though the relict nature of most of the cave populations is well admitted, it remains difficult to be precise concerning the evolutionary trends and the moments of the specific differentiation of the planarians. Moreover the occurrence of high diploid chromosome numbers in hypogeous species, though well established, is not yet to be considered as a permanent rule relating the chromosome complement to the habitat.

A final question to be emphasized concerns the karyotype similarities within congeneric species. A relative uniformity appears mainly at the level of chromosome morphology and for the number of elements. So the karyological data are well in agreement with the taxonomic conventions. Nevertheless, more extensive research is needed for a better knowledge of the species affinities.

\section{SUMMARY}

Very few studies have been involved with karyology in Planarian living in total darkness. The first results indicate however, that most of the hypogeous Paludicoles have a diploid chromosome number notably superior to the similar surface forms.

In another connection a relative uniformity of the morphology of the chromosome is observed in the same group, so that the studied karyotypes show a similar general aspect.

\section{RÉSUMÉ}

Peu nombreuses sont les études portant sur la caryologie des Planaires obscuricoles. Les premiers résultats soulignent toutefois que la plupart des Paludicoles hypogés possède un nombre chromosomique diploïde nettement supérieur à celui de leurs congénères de surface.

Par ailleurs, au sein d'un même genre, s'observe une relative uniformité de la morphologie des chromosomes se traduisant par l'obtention de caryotypes d'allure générale comparable.

\section{REFERENCES}

Aeppli, E. 1951. Die Chromosomenverhältnisse bei Dendrocoelum infernale (Steinmann). Rev. suisse Zool., 58, 511-518.

Benazzi, M. 1938. Tricladi Paludicoli della Sardegna. Arch. Zool. It., 25, 85-94. 
Benazzi, M. and Benazzi-Lentati, G. 1975. The cytogenetics of Platyhelminthes. Gebrüder Borntraeger, Berlin-Stuttgart. In press.

Benazzi, M. and Gourbault, N. 1973. Données préliminaires sur la caryologie de la Planaire hypogée Plagnolia vandeli de Beauchamp et Gourbault, 1964. C.R. Acad. Sc. Paris, 277, Sér. D, 1337-1340.

Benazzi, M. and Gourbault, N. 1974. Recherches caryologiques sur quelques Dendrocoelidae hypogés. C.R. Acad. Sc. Paris, 278, sér. D, 1051-1054.

Benazzi, M. and Gourbault, N. 1975. Etude caryologique de quelques populations hypogées de la Planaire Phagocata (Fonticola) vitta (Dugès, 1830). Caryologia, 27, 467-484.

Dahm, A. G. 1958. Taxonomy and ecology of five species groups in the family Planariidae. 1 vol., Malmö (Nya Litografen), 241 p.

Dahm, A. G. 1961. Cytotaxonomical analyses of four Dendrocoelum species (Turbellaria Tricladida Paludicola). Lunds Univ. Arsskr., n.f. Avd. 2, 57, 1-44.

Dahm, A. G. 1964. The taxonomic relationships of the European species of Phagocata based on karyological evidence. Arkiv f. Zool. Stockholm, 16, 24, 481-509.

Gourbault, N. 1972. Recherches sur les Triclades paludicoles hypogés. Mém. Mus. Natn. Hist. nat. Sér. A., 73, 1-249.

Gourbault, N. 1975. Etude caryologique des Triclades hypogés: 2. Dendrocoelum coiffaiti de Beauchamp. Ann. Spéléol., 30, 427-432.

Gourbault, N. and Benazzi, M. 1974. Etude caryologique du Triclade hypogé Dendrocoelopsis chattoni (de Beauchamp). Ann. Spéléol., 29, 621-626.

Henry, J. P. 1972. Etude de la constitution chromosomique des Asellidae (Crustacea isopoda). Bull. Soc. Zool. France, 97, 119-131.

Juberthie, C. 1956. Nombres chromosomiques chez les Sironidae, Trogulidae, Ischyropsalidae, Phalangiidae (Opilions) C.R. Acad. Sc., Paris, 242, 2860-2862.

Levan, A., Fregda, K. and Sandberg, A. A. 1964. Nomenclature for centromeric position on chromosomes. Hereditas, 52, 201-220.

Reygrobellet, J. L. 1974. Garnitures chromosomiques de quelques espèces du genre Niphargus (Amphipode gammaridé troglobie), Ann. Spéléol. 29, 97-104.

Saltet, P. 1967. La formule chromosomique de l'Orthoptère cavernicole Troglophilus neglectus (Rhaphidophoridae). C.R. Acad. Sc. Paris, 265, sér. D, 1313-1316. 